\title{
SPECTROSCOPIC INVESTIGATIONS OF LUMINOUS EMISSION-LINE OBJECTS
}

\author{
ANGELO CASSATELla, ROBERTO NESCI, and ROBERTO VIOTTI \\ Laboratorio di Astrofisica Spaziale, Frascati, Italy
}

\begin{abstract}
Emission lines are frequently observed in the spectra of the high luminosity stars, indicating the presence of extended atmospheric envelopes. We are investigating the physical characteristics (differential expansion velocity, density, extension, mass loss) and the origin of these envelopes in relation to the high luminosity of the parent star, and its evolutionary stage. Some results are presented concerning Eta Car, S Dor, HD 34664, P Cyg, AG and HR Car, and two WR stars.
\end{abstract}

References to Table I on the following page

[1] Alexander, J. D. and Thackeray, A. D.: 1971, Observatory 91, 25.

[2] Beals, C. S.: 1950, Publ. Dominion Astrophys. Obs. 9, 1.

[3] Bond, H. E. and Landolt, A. U.: 1970, Publ. Astron. Soc. Pacific 82, 313.

[4] Caputo, F. and Viotti, R.: 1970, Astron. Astrophys. 7, 266.

[5] de Groot, M.: 1969, Bull. Astron. Inst. Neth. 20, 225.

[6] Feinstein, A. and Marraco, H. G.: 1974, Astron. Astrophys. 30, 271.

[7] Gerola, H. and Viotti, R.: 1967, Mem. Soc. Astron. It. 38, 3.

[8] Hoyle, F., Solomon, P. M., and Woolf, N. J.: 1973, Astrophys. J. 185, L89.

[9] Martini, A.: 1969, Astron. Astrophys. 3, 443.

[10] Robinson, G., Hyland, A. R., and Thomas, J. A.: 1973, Monthly Notices Roy. Astron. Soc. 161, 281.

[11] Smith, L. F.: 1968, Monthly Notices Roy. Astron. Soc. 140, 409.

[12] Viotti, R.: 1967, Proc. Padova Meeting of the It. Astron. Society.

[13] Viotti, R.: 1968, Mem. Soc. Astron. It. 39, 105.

[14] Viotti, R.: 1969, Astrophys. Space Sci. 5, 323.

[15] Viotti, R.: 1970, Mem. Soc. Astron. It. 41, 513.

[16] Viotti, R.: 1971, Publ. Astron. Soc. Pacific 83, 170.

[17] Viotti, R. and Nesci, R.: 1974, Inf. Bull. Var. Stars, No. 878. 
ANGELO CASSATELla et AL.

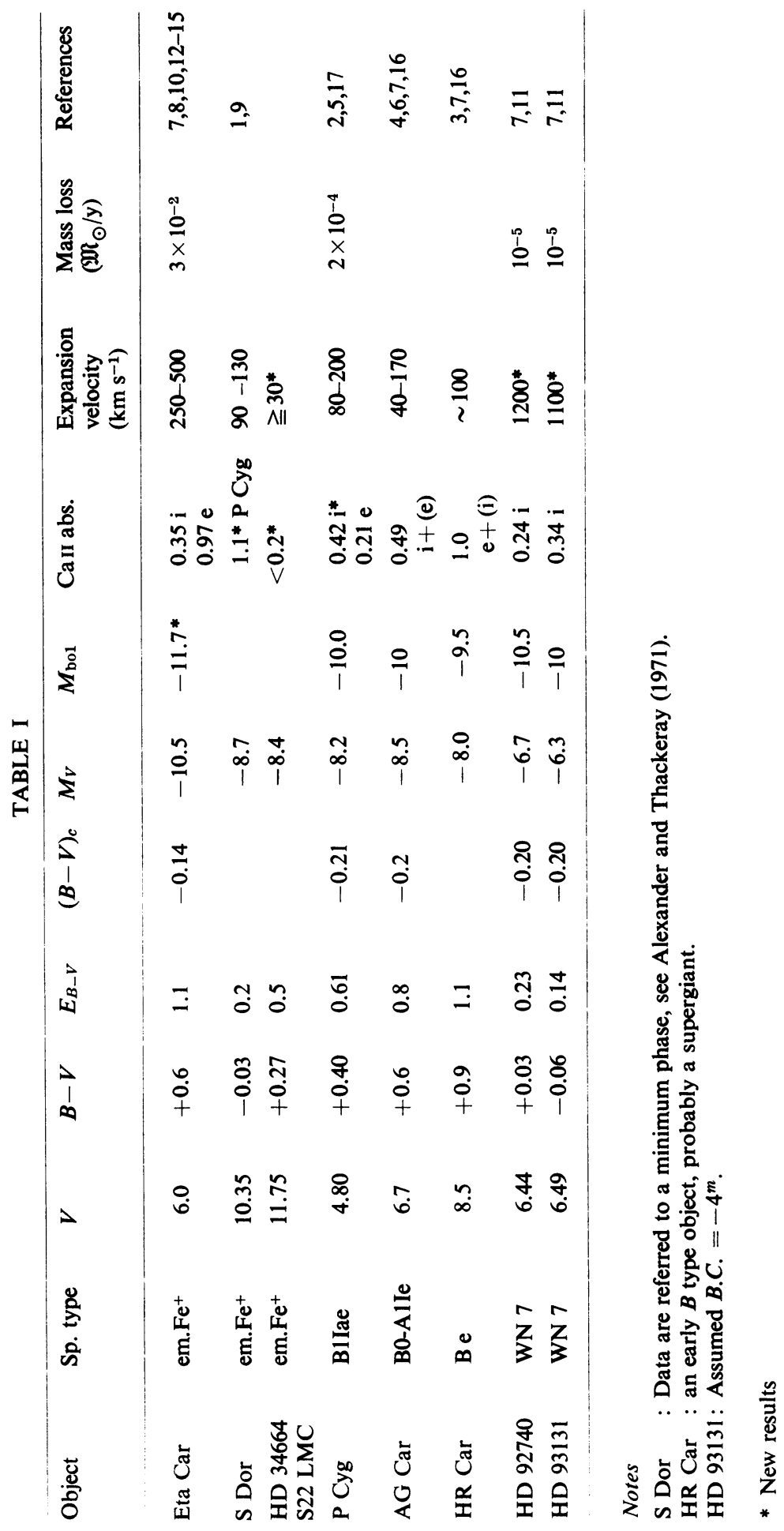

